\title{
Seismic performance of traditional half-timbered walls: experimental results
}

\author{
Poletti Elisa ${ }^{1, a}$ and Vasconcelos Graça ${ }^{1, b}$ \\ ${ }^{1}$ ISISE, University of Minho, Department of Civil Engineering, Campus de Azurém, \\ 4800-058 Guimarães, Portugal \\ aelisapoletti@civil.uminho.pt braca@civil.uminho.pt
}

Keywords: half-timbered, infill, retrofitting, steel plates, NSM, energy dissipation.

\begin{abstract}
Introduction
Half-timbered structures constitute an important cultural heritage of many countries, since they represent a typical anti-seismic construction adopted worldwide [1][2]; therefore, their preservation is of the utmost importance. Although recent earthquakes have pointed out the good seismic behaviour of this kind of structures, few experimental studies are available on the performance of traditional half-timbered walls and their retrofitting solutions and mainly only qualitative information is available of the seismic response of such structures. Due to this lack of information, an extensive experimental campaign was carried out, performing in-plane cyclic tests on real scale half-timbered and timber frame walls, adopting connections and dimensions encountered in real structures and considering different infill types (brick masonry and lath and plaster).

Moreover, keeping in mind the great rehabilitation effort that has been carried out in recent years on such buildings, such in the case of the Portuguese Pombalino buildings in Lisbon, it is important to study the effect of strengthening on traditional timber-frame walls. To do this, retrofitting solutions have been applied to traditional walls and tested under cyclic loading. Both traditional and innovative techniques have been considered, namely bolts, steel plates and NSM steel flat bars.

Results on the behaviour of both unreinforced and retrofitted walls are analysed and their seismic behaviour is discussed.
\end{abstract}

\section{Experimental campaign}

To study the behaviour of traditional timber frame walls an extensive experimental campaign has been carried out taking into consideration parameters such as vertical pre-compression level, type of infill and type of strengthening.

Wall specimens. The wall specimens chosen were built by specialized carpenters. All the connections between the vertical posts and the beams are half-lap joints, as well as the connections between the two diagonals of the St. Andrew's crosses, whilst the connections between the diagonal and the main frame are simple contact ones (see Fig. 1a). The walls were built in real scale, with realistic cross sections for all the elements (see Fig. 1b).

After the completion of the timber frame, part of the walls was filled with distinct types of infill to obtain the traditional half-timbered walls which characterize many cities in the world. Thus, besides the walls without any infill material, two additional groups of walls were considered, namely (1) timber frame walls with brick masonry infill and (2) lath and plaster walls. The use of different types of infill aimed also to assess its influence on the cyclic behaviour of timber frame walls.

For the masonry infill, the masonry pattern consists of double leaf masonry with transversal series 
of bricks every two rows of horizontal double leaf masonry, as detailed in Fig. 1c. It was decided to use modern materials available in the market mainly to represent what it is being done nowadays in rehabilitation works, in order to reduce rehabilitation costs.

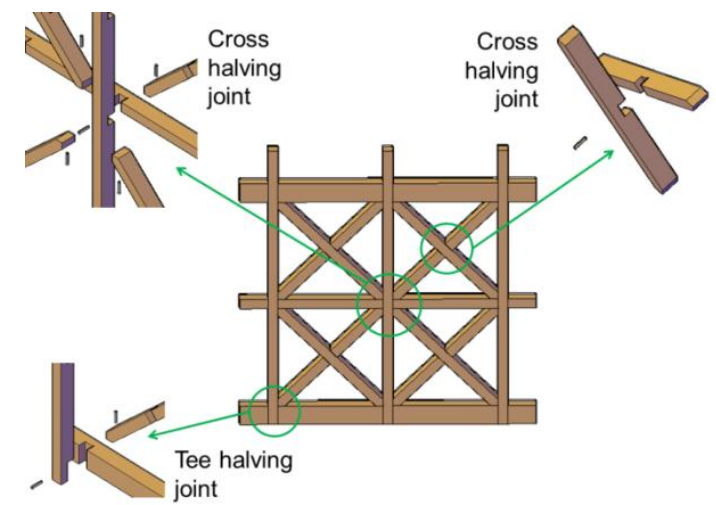

(a)
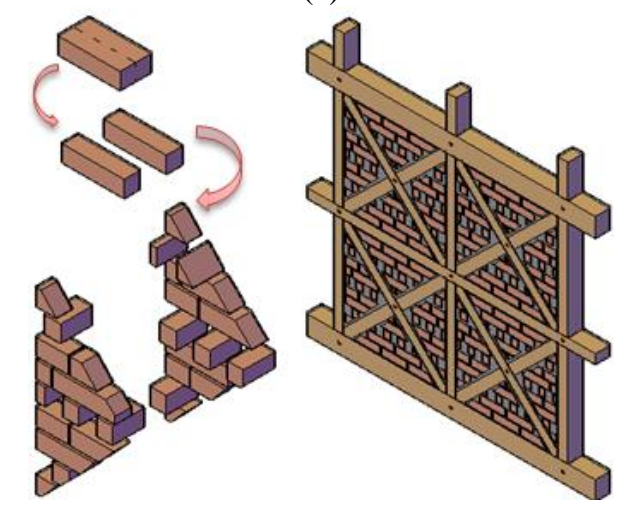

(c)

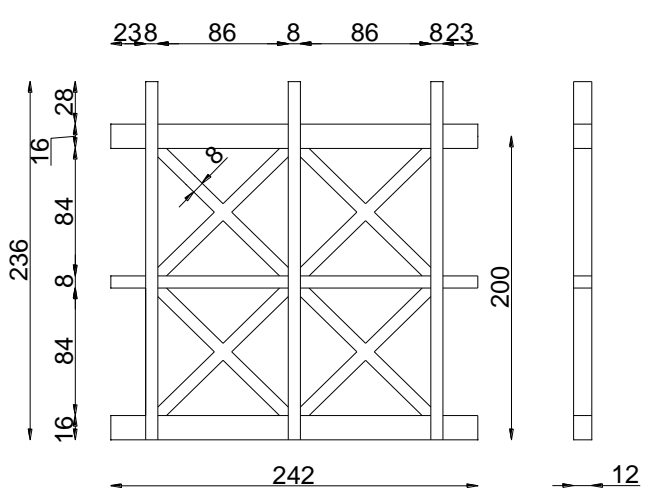

(b)
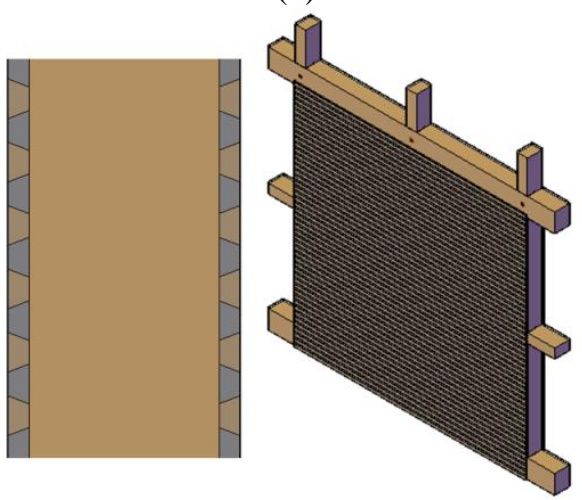

(d)

Fig. 1 Wall specimens: (a) connections used; (b) dimensions of elements in cm; (c) masonry infill; (d) lath and plaster

Test setup and procedure. The cyclic tests were carried out using the setup illustrated in Fig. 2a. The application of the vertical load was done by means of vertical hydraulic actuators applied directly on the three posts of the walls and connected to the bottom beam through steel rods which connected the actuators to a hinge welded in the bottom beam, so that the actuators were able to follow the horizontal movement of the wall. The horizontal displacement was applied to the top timber beam through a hydraulic servo-actuator, which was connected by means of a 3-D hinge to the reaction wall and a two-dimensional hinge was connecting it to the wall specimen.

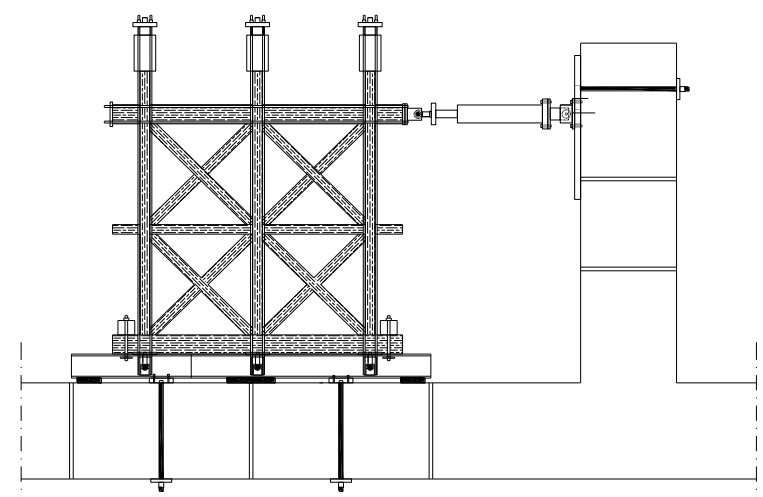

(a)

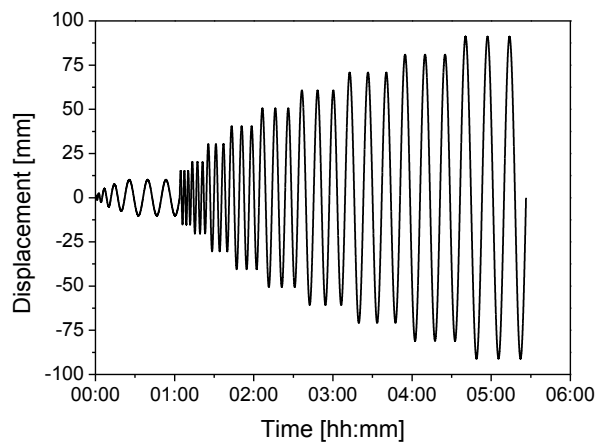

(b)

Fig. 2 (a) Test setup used in the experimental campaign; (b) test procedure

The cyclic procedure adopted during the tests was based on standard ISO DIS 21581[3]. In order to 
better capture the highly non-linear behaviour of the walls, additional steps were added in the procedure, considering an increment in the applied displacement of 10\% (see Fig. 2b). Two different test speeds were adopted: one for displacement up to $10 \%$ of the maximum displacement (namely $0,05 \mathrm{~mm} / \mathrm{s}$ ) and one for the remaining displacement levels (namely $0,35 \mathrm{~mm} / \mathrm{s}$ ).

Moreover, each wall type was subjected to two vertical pre-compression levels: (1) $25 \mathrm{kN} /$ post, for a total of $75 \mathrm{kN}$, corresponding to the vertical load expected for these walls, considering their selfweight, the weight of the floors and live loads and (2) $50 \mathrm{kN} /$ post, for a total of $150 \mathrm{kN}$, in order to take into account a possible change of use of the structure.

Type of strengthening. The tested walls were repaired and retrofitted. The main repairs performed consisted on repairing the masonry blocks applying a fast setting natural cement, repairing damaged timber elements with a timber prosthesis or substituting a timber element when the damage was too extensive. Analysing the results of unreinforced timber frame walls, it was decided to strengthen the walls using three techniques, two traditional and one innovative. The first traditional technique adopted was to apply bolts to each half-lap joint connection of the main frame (Fig. 3a). This technique is only feasible for infill walls, since the infill confines the frame, guaranteeing a higher strength. The bolts used had a diameter of $10 \mathrm{~mm}$ and a total length of $160 \mathrm{~mm}$ and were a class 8.8 steel fasteners. They were inserted in pre-drilled holes. For this type of intervention, low tech equipment and workmanship are required; moreover the intervention is removable as well as economical.

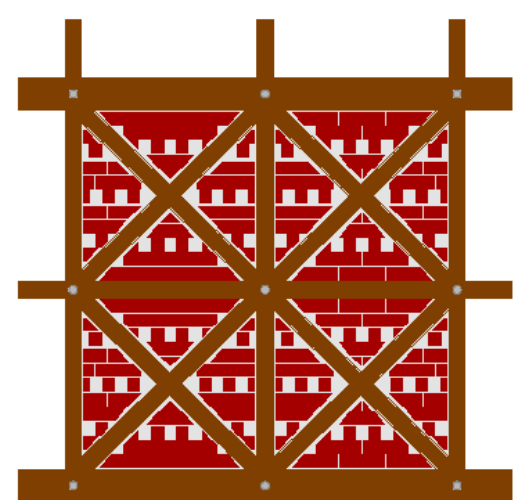

(a)

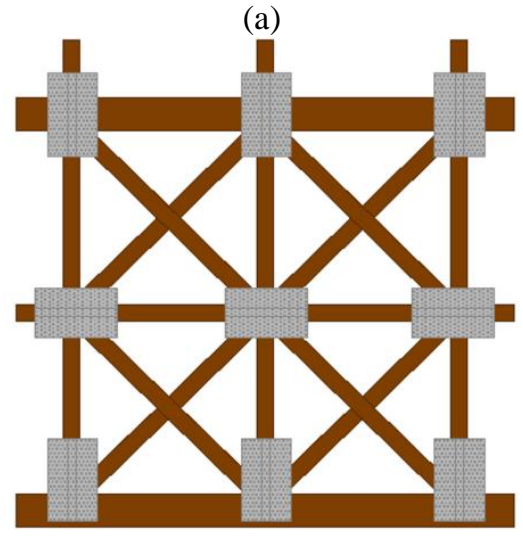

(c)

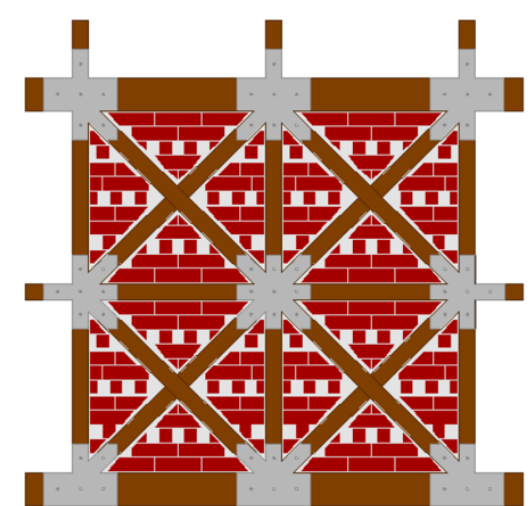

(b)

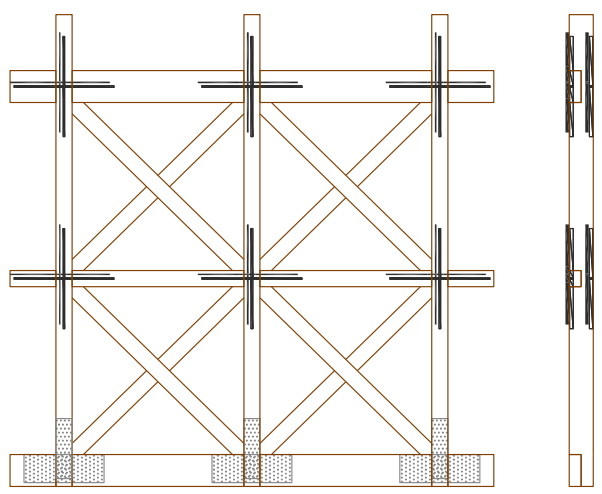

(d)

Fig. 3 Strengthening solutions adopted: (a) bolts; (b) custom steel plates; (c) commercial steel plates; (d) steel flat bars inserted with NSM technique

The second traditional technique consists of applying steel plates to the main connections of the frame, as shown in Fig. 3b,c. For infill walls, custom steel plates made in zinc-galvanized steel and having a thickness of $3 \mathrm{~mm}$ were used, with a star-shape (see Fig. 3b) to better fit the frame. They were secured to the timber frame with bolts. For timber frame walls without infill, commercial steel plates were used (Fig. 3c). The steel plates were secured with bolts and screws, to better distribute the stresses in the plates. Two different configurations have been tested for timber frame walls, one 
linking the main elements of the connection, post and beam, with the diagonals and one linking only the main members, leaving the diagonals free of strengthening. Perforated plates (Rothoblaas plates PF703085 $\left.\left(140 \times 400 \mathrm{~mm}^{2}\right)\right)$ made of steel S250GD and having a thickness of $2 \mathrm{~mm}$ were used.

The innovative solution adopted consisted of applying steel flat bars in the connections inserted with the near surface mounted technique (NSM). This technique could not be applied to the bottom connections, since the anchorage length was not sufficient. Therefore, steel plates were applied, as done in the previous retrofitting solutions. To perform the retrofitting of the walls, cuts were opened in the elements, having a width of $12 \mathrm{~mm}$ and a depth of $23 \mathrm{~mm}$ to accommodate the flat bars with a section of $8 \times 20 \mathrm{~mm}^{2}$. The cuts were filled with structural timber glue, then the steel flat bars were inserted and additional glue was added if necessary to completely fill the cuts. This intervention is potentially invisible, but not removable. The flat bars were inserted in each connection (Fig. 3d); cross-shaped bars welded together with a notched connection in the middle were used.

\section{Results on unreinforced walls}

Cyclic test results performed on both infill and timber frame walls are here presented and a discussion of their general behaviour is reported.

All unreinforced half-timbered walls subjected to the same vertical pre-compression level present a similar behaviour. The walls tested with the lower vertical pre-compression (UIW25) present a predominant rocking behaviour (see Fig. 4a), characterized by the S-shape of the forcedisplacement diagrams, with a significant vertical uplift of the posts. In Fig. 4, complementary to the hysteresis diagrams, the evolution of the vertical displacements measured by LVDTs placed at the bottom connections of the walls versus the top lateral displacement of the walls is also shown. It is seen that the lateral posts were uplifting as much as $50 \mathrm{~mm}$, pointing out the important rotation experienced by the walls.

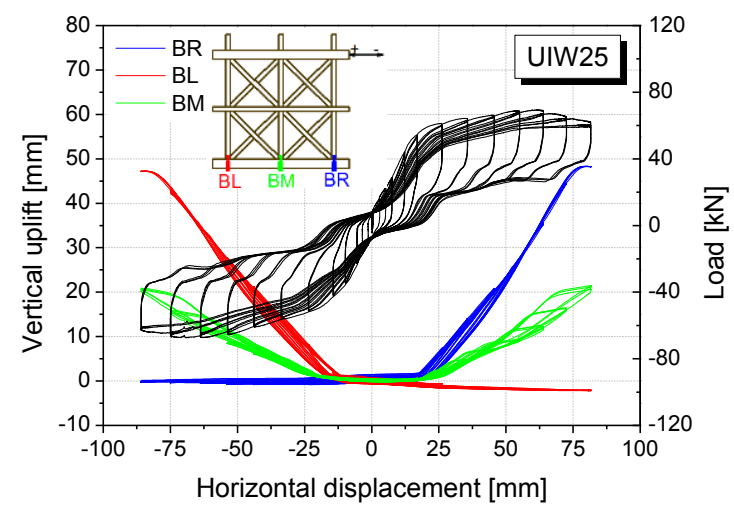

(a)

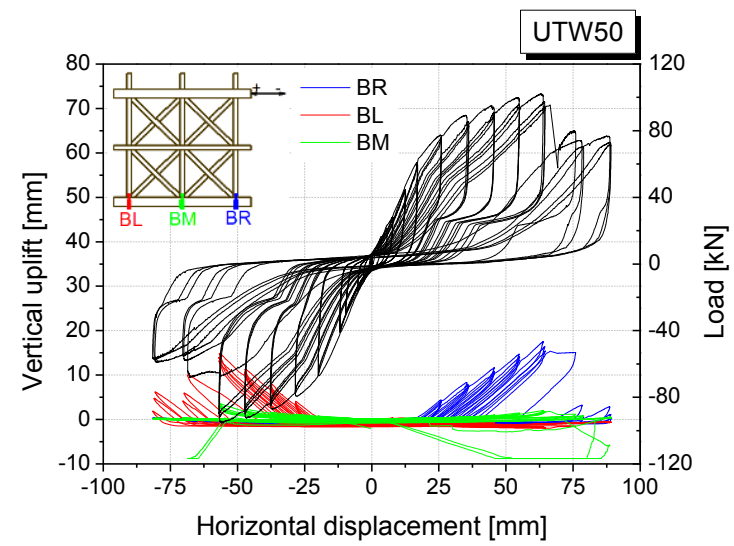

(c)

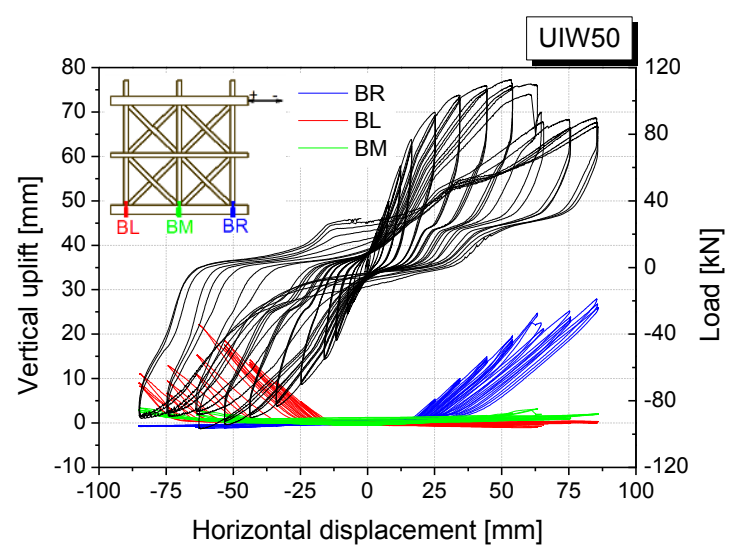

(b)

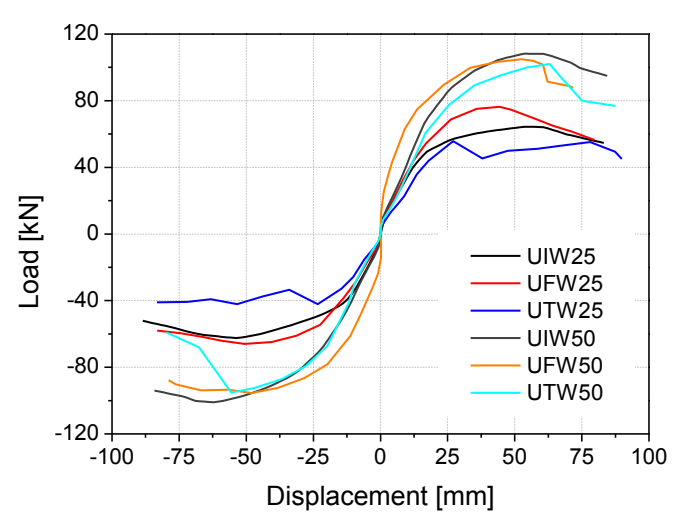

(d)

Fig. 4 Results on unreinforced walls: (a) UIW25; (b) UIW50; (c) UTW50; (d) envelope curves 
The rocking mechanism was evident even in masonry infill walls submitted to the higher level of vertical pre-compression load (UIW50), even if in this case a shear component was clearly present (Fig. 4b). The uplift of the vertical posts occurred during these tests too, in a lower amount, but it still conditioned the shape of the hysteretic loops. The walls exhibit a progressive loss of stiffness, even though the ultimate load does not differ greatly from the maximum one.

If the form of the hysteretic loops is compared with the uplift of the vertical posts for the same horizontal displacement, one can notice that: (1) the change in stiffness in the loading branch starts when the lateral posts start uplifting; (2) the plateaux that occur in the unloading branch of each cycle occur when the bottom connections start closing.

The increase of vertical pre-compression led to an increase of initial stiffness of $17 \%$ and of load capacity of $65 \%$.

The hysteresis diagrams found for lath and plaster walls (UFW) for both vertical load levels are very similar to those observed for half-timbered walls and will not be presented here. The confining effect given by the timber strips assured an important lateral stiffness, which resulted to be higher than that of masonry infill timber frame walls, as can be seen from the envelopes curves in Fig. 4d. Timber frame walls (UTW walls) exhibited a different behaviour in relation to infill walls. The shear resisting mechanism predominated in the lateral response over the minor flexural component. But, as it can be noticed from the hysteretic diagrams (Fig. 4c), the walls experienced severe pinching. This appears to indicate that the pinching can in a certain extent be avoided by the infill, both brick masonry and lath and plaster. Moreover, the unloading branch of the various loops is more regular, even if the plateau characterizing the post uplifting is still present.

As it can be deduced from the analysis done until now, the presence of infill greatly changes the response of timber frame walls to cyclic actions. The type of infill, though, does not appear to overly influence their behaviour.

Moreover, the amount of vertical pre-compression applied to the walls greatly influences their behaviour. It changes its response to cyclic actions, since a higher pre-compression leads to a stiffening of the wall and to a greater load capacity. UIW walls with brick masonry infill gained $64.7 \%$ in terms of maximum load, while only losing $2.8 \%$ in terms of ultimate displacement. UFW walls gained $29 \%$ in terms of maximum load, but their ultimate displacement decreased of $2.8 \%$. In case of UTW walls an increase of vertical pre-compression resulted in an increase on the lateral resistance of $104.6 \%$, with a loss in terms of ultimate displacement of only $2.7 \%$.

Typical damages. Typical damages for all walls were concentrated in the connections, pointing out the key role that they play in the overall response of the wall. Typical damages consisted in uplifting of the bottom connections (Fig. 5a), opening out-of-plane of the connections and nail pullout, cracks in masonry blocks, detachment between masonry and timber frame, crushing of the connection (Fig. 5b) (particularly for the higher vertical load level), tearing off of the connections (Fig. 5c).

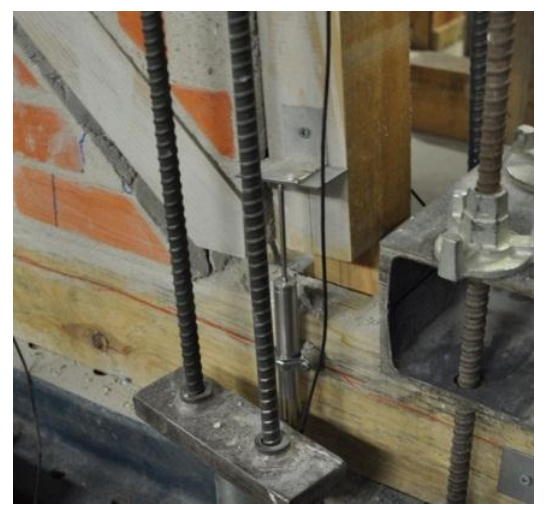

(a)

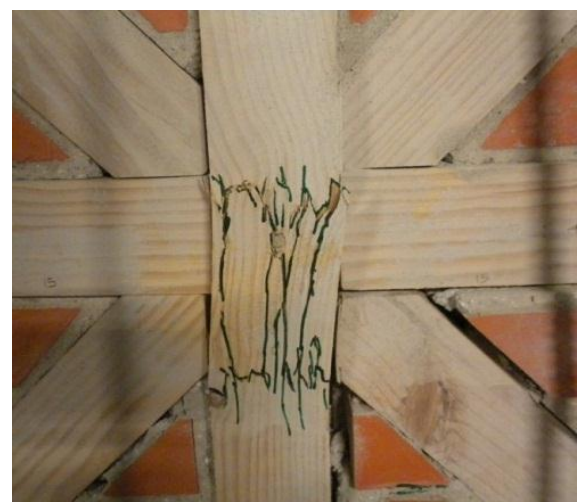

(b)

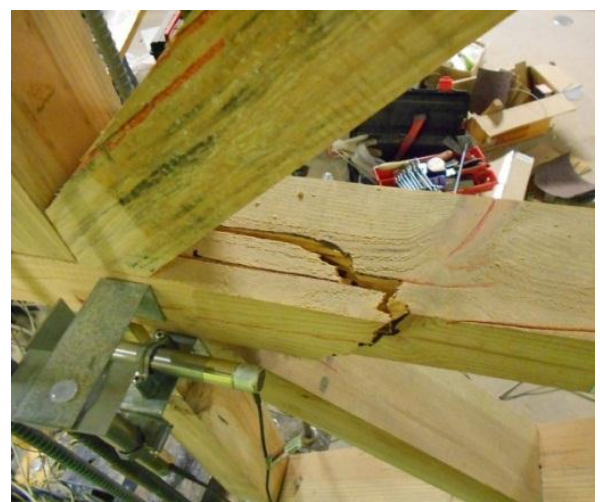

(c)

Fig. 5 Typical damages in walls: (a) uplifting of bottom connections in infill wall; (b) crushing of central connection in infill wall; (c) tearing off of half-lap joint in timber frame. 
Notice that heavier damages were experienced in timber frame walls, since the confining effect of the infill was not present and the timber frame suffered greater deformations. The timber elements experienced severe damages due to the shear effect of the diagonals, which would cut into the elements, tearing them off. On the other hand, the absence of infill led to minimal uplifting in timber frame walls, preventing the rotation of the wall.

\section{Results on retrofitted walls}

All retrofitted walls showed an improvement in comparison to unreinforced walls, being it in terms of strength and stiffness or in terms of general behaviour of the wall.

Comparing the hysteretic behaviour of the strengthened walls with bolts at connections and the corresponding unreinforced half-timbered walls, it is observed that there is no great gain in terms of ultimate capacity and stiffness. In fact, for the lower vertical load level, the gain in terms of maximum load was of $23.7 \%$, while for the higher vertical load level it lost $5 \%$. In terms of ultimate displacement, the walls gained $5.7 \%$ and $0.2 \%$ respectively (Fig. 6a).

However, the general behaviour of the walls changes; the plateau caused by the uplifting of the vertical post from the base beam is still clearly present, but it is less pronounced and the unloading branch of the cycles is smoother. In fact, vertical uplifting in the posts decreased of approximately $40 \%$ for both load cases. The bolts contribute to the resistance to tensile forces present in the bottom overlapped connections, ensuring a degree of continuity to the bottom connections.

For infill walls retrofitted with steel plates (Fig. 6b) the gain in terms of maximum load is considerable, reaching an increment of $60.4 \%$. Moreover, it is observed that the initial stiffness increased of $14 \%$ and the ultimate displacement is of the same size order. However, the displacement imposed to the walls does not correspond to the maximum displacement capacity, but due to limitations of the equipment it was not possible to continue the test. A similar behaviour was observed for both vertical load levels. It should be pointed out that the use of star shape steel plates, linking the main elements of the connection (post and beam) to the diagonals gives a significant additional strength and stiffness to the wall. In fact, for this type of strengthening, the values of initial lateral stiffness are comparable for the two vertical load levels, meaning that for such a strong retrofitting technique, the effect on the amount of vertical load becomes secondary.

For timber frame walls it was observed how linking the diagonals to the main frame greatly stiffened the walls inducing out-of-plane movements [4], thus a second strengthening was done linking only the main elements of the frame (post and beam) with the steel plates. This solution allowed the walls to gain significantly both in terms of stiffness and load capacity, without compromising the displacement capacity (see Fig. 6c). In fact, in terms of maximum load, the walls gained $183 \%$ and $35 \%$ for the lower and higher pre-compression load respectively, while lost $5 \%$ and $3.5 \%$ in terms of ultimate displacement respectively. On the other hand, this retrofitting solution led to severe pinching in the timber walls. Similarly to the retrofitting with custom plates, also in this case, the vertical load has only marginal influence in terms of maximum load, even if it influences the initial stiffness, being higher for the higher vertical pre-compression.

Concerning the NSM steel flat bars retrofitting, it was observed that it was more appropriate for timber frame walls, since the confining effect of the infill did not allow to take full advantage of the deformation capacity of the timber elements with the embedded bars. Low values of strain were recorded at the bars in infill walls and the improvement in terms of lateral resistance was of $62 \%$ and $30 \%$ for the walls submitted to the lower and higher pre-compression load levels respectively. Nonetheless, the behaviour of the wall change from a flexural one to a mainly shear one, so the retrofitting was able to guarantee the expected results.

For timber frame walls from the comparison between the unreinforced and retrofitted walls (Fig. 6d) it is clearly visible a considerable improvement of the lateral response, with the increase on the lateral resistance of about $197 \%$ and of $64 \%$ for the retrofitted walls submitted to the lowest and highest levels of pre-compression respectively. Notice that in this case too, the vertical load 
level has minimal influence on the results, reaching the walls similar values of load capacity and stiffness. Since no severe damage was observed in the walls, the timber frame wall was submitted to a monotonic test after the cyclic test in order to characterize the failure mechanism. The lateral resistance obtained of $179 \mathrm{kN}$ (Fig. 6d) was $121 \%$ higher than the one recorded in the unreinforced timber frame wall, which confirms that the increase on the lateral resistance recorded in the cyclic test did not mobilize all the contribution of the flat steel bars and does not correspond to the failure configuration of the wall.

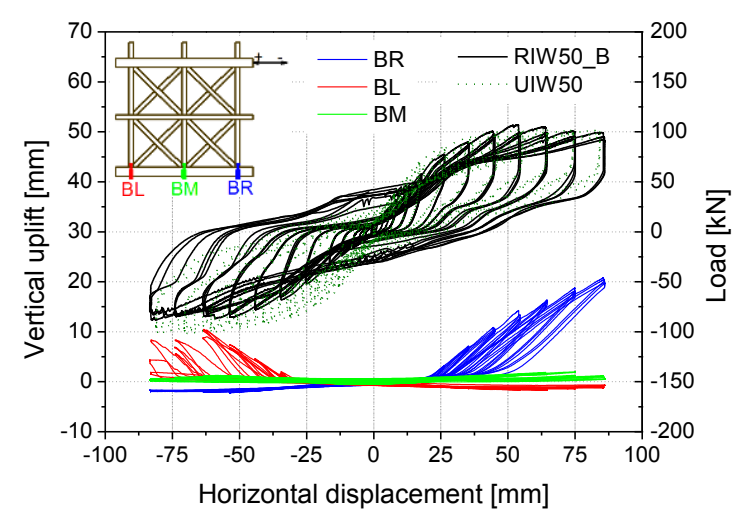

(a)

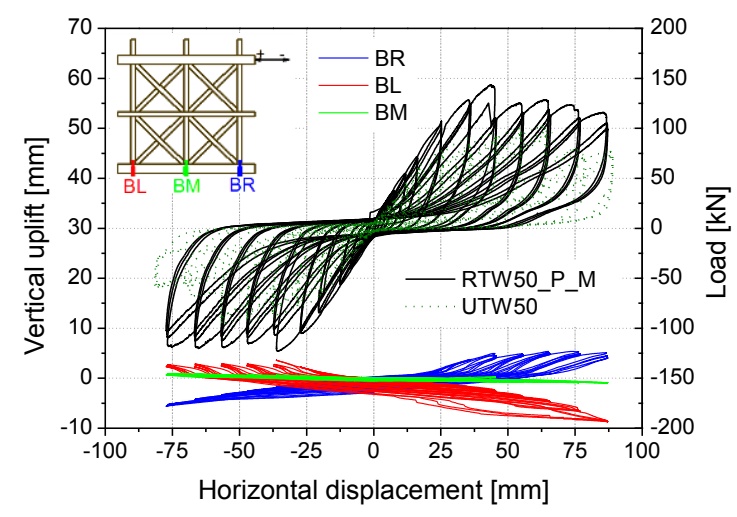

(c)

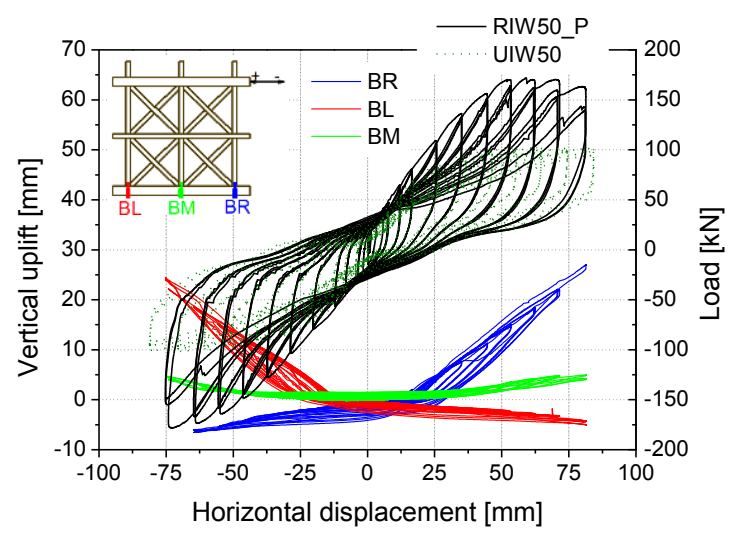

(b)

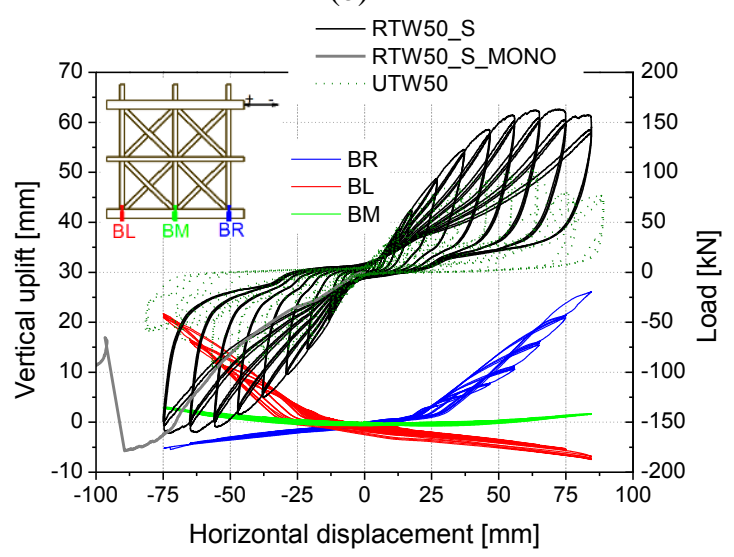

(d)

Fig. 6 Results on retrofitted walls: (a) bolts strengthening; (b) steel plates strengthening, infill wall; (c) steel plates strengthening, timber frame wall; (d) NSM strengthening, timber frame wall.

All walls strengthened with steel flat bars experienced pinching, but it was more severe for timber frame walls, as observed for walls retrofitted with steel plates. It appears that pinching manifests itself more when there is less confinement, being it given by the infill or by the strengthening.

Typical damages. As was the case for unreinforced walls, in retrofitted specimens too the damages are concentrated at the connections. The retrofitted walls experienced severe damages after failure, contrary to what observed in unreinforced walls. Nonetheless, in most cases, the strengthening was still able to work and guarantee an adequate resistance of the wall.

Walls strengthened with bolts exhibited severe damages. The walls develop damages in the central connections, which failed with tearing off of the central beam (Fig. 7a) and crushing of the central post, and the nailed connections between the diagonals and the main frame detached.

In case of walls retrofitted with steel plates the damages observed were similar for all walls and they consisted in: (1) failure of the overlapped connection linking two diagonal member in a cell for walls in which the steel plates linked the diagonals to the main frame (Fig. 7b); (2) failure of the central middle connection for walls where the diagonals were not linked to the main frame through the steel plates (Fig. 7b). The creation of strong retrofitted points (steel plates linking main frame 
with diagonals) resulted in the failure of the weakest zones of the wall, which were the overlapped connection of the diagonals. Notice that no damages were observed in the main wood members of the connection. An ovalization of the holes for the bolts in the diagonals was observed for timber frame walls too. When the diagonals are free to move, the failure occurs in the main member of the frame (Fig. 7c), due to the shear action imposed by the diagonals elements.

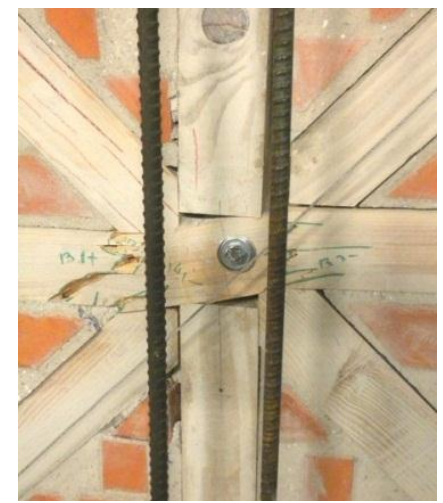

(a)

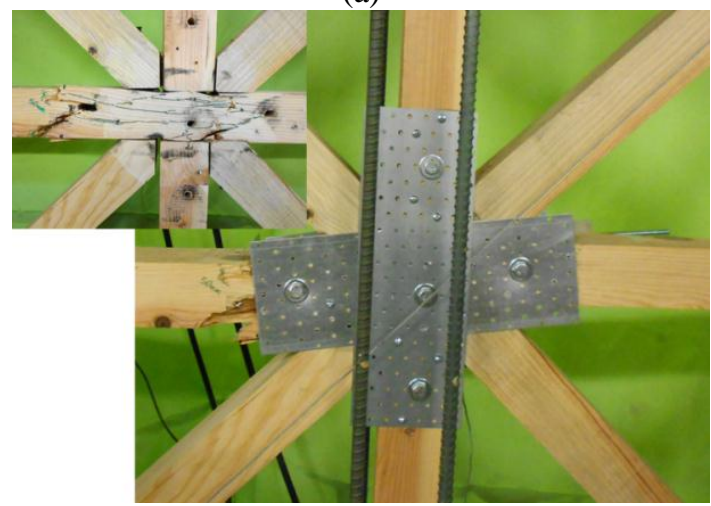

(c)

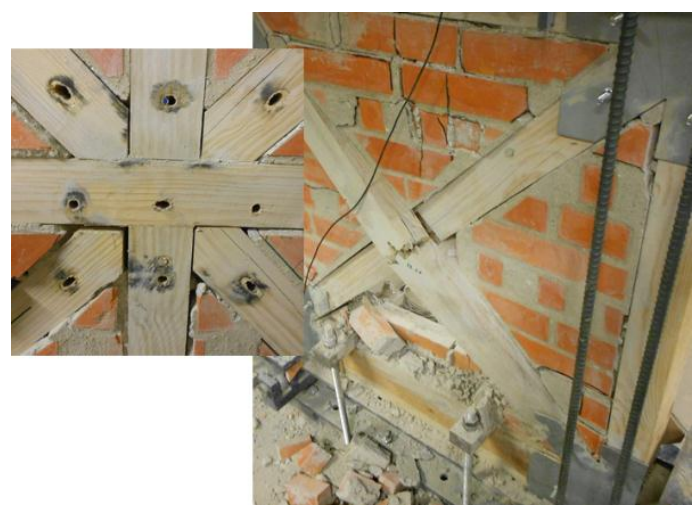

(b)

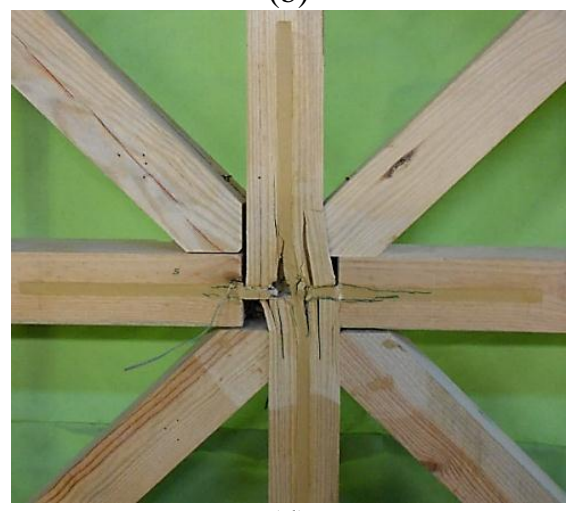

(d)

Fig. 7 Typical damages in walls: (a) tearing of timber element in infill wall retrofitted with bolts; (b) failure of half-lap joint of diagonals in infill wall retrofitted with steel plates; (c) failure of central connection in timber frame wall retrofitted with steel plates; (d) failure of steel bar at central connection in timber frame wall.

For infill walls with NSM retrofitting plastic deformation were observed in the steel bars, but no failure occurred. For the timber frame wall tested monotonically at the end of the cyclic test, failure occurred at the central connection, see Fig. 7d, associated to the failure of the bar and further propagation of cracking in the wood. With the deformations reached, the approximate strength estimated in the bars for deformation of $6 \%$ was of $627 \mathrm{MPa}$, a value $50 \%$ higher than the yield strength. For both wall typologies, the bars deformed in the plastic regime.

\section{Seismic parameters and comparison}

In the seismic design of new timber structures or in the rehabilitation of existing structures, including historic timber frame walls, the study of the seismic performance is of paramount importance. Since the seismic response of timber structures is very complex and time dependant, a better understating of the hysteretic factors that govern the problem is important for a safe and economical seismic design or for the adoption of the most adequate retrofitting measures.

A major parameter used for the assessment of the seismic performance of the seismic behaviour is the ability of a structural element to dissipate energy during cyclic testing. The energy dissipated by the walls at each cycle is computed by calculating the area enclosed by the loop in the loaddisplacement diagram and it represents the amount of energy dissipated during the cyclic loading. The energy can be dissipated through friction in the connections, yielding of nails, yielding and 
deformation of the retrofitting bolts, steel plates and bars and permanent deformation accumulated in the walls as observed during the tests.

Other parameters that can be analysed are initial stiffness and stiffness degradation, ductility and the equivalent viscous damping ratio.

Dissipated energy for unreinforced walls is presented in Fig. 8a. Timber walls presented the lower amount of dissipated energy for both vertical load levels. This can be attributed to the strong pinching present in these walls, which clearly diminishes the dissipative capacity of the walls. For both load levels, lath and plaster walls had a higher dissipative capacity, showing how this alternative infill guarantees a good seismic behaviour.

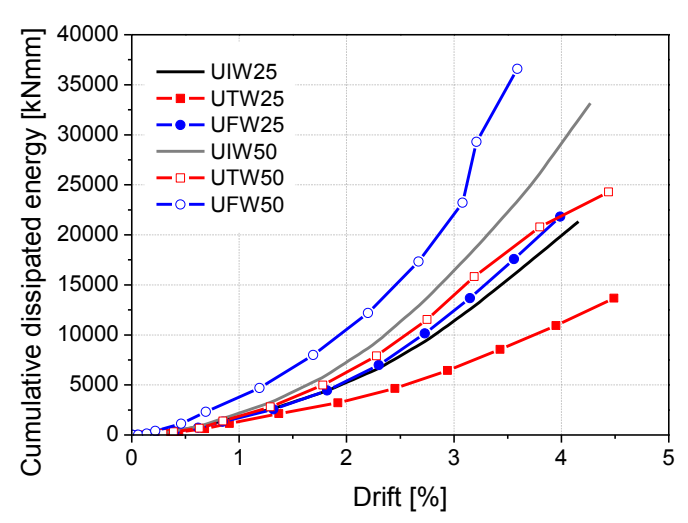

(a)

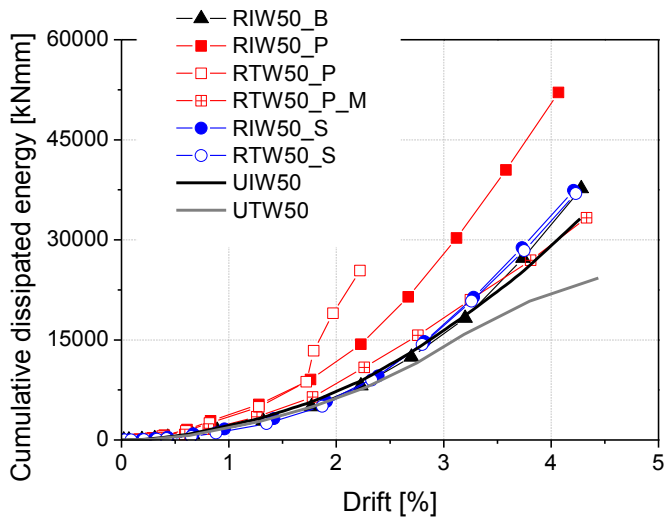

(b)

Fig. 8 Cumulative dissipated energy: (a) average values of unreinforced walls; (b) values of retrofitted walls, higher vertical load

Taking into account the dissipative capacity of retrofitted walls (Fig. 8b), all retrofitting techniques adopted were able to guarantee greater energy dissipation during the tests. The highest dissipative solution is provided by the retrofitting technique with steel plates linking the diagonals. For the walls tested without linking the diagonals, the dissipative capacity was lower.

Retrofitting with bolts showed results comparable to the ones obtained in unreinforced walls, improving only for high values of drift in case of the higher pre-compression load, given that the solution changed the failure mode of the wall.

Table 1 Comparison among values of seismic parameters for unreinforced and retrofitted walls

\begin{tabular}{|c|c|c|c|c|c|c|c|c|c|}
\hline \multirow[b]{2}{*}{$\begin{array}{c}\text { VERT } \\
\text { LOAD } \\
{[\text { kN/post] }}\end{array}$} & \multirow[b]{2}{*}{ PARAMETER } & \multicolumn{4}{|c|}{ INFILL WALLS } & \multicolumn{4}{|c|}{ TIMBER FRAME WALLS } \\
\hline & & UIW & BOLT & $\begin{array}{l}\text { STEEL } \\
\text { PLATE }\end{array}$ & NSM & UTW & $\begin{array}{c}\text { STEEL } \\
\text { PLATE } \\
\text { WITH } \\
\text { DIAG }\end{array}$ & $\begin{array}{c}\text { STEEL } \\
\text { PLATE } \\
\text { NO } \\
\text { DIAG } \\
\end{array}$ & NSM \\
\hline \multirow{5}{*}{25} & MAX LOAD [kN] & 63.85 & 76.86 & 157.36 & 102.99 & 48.92 & 177.30 & 139.42 & 145.06 \\
\hline & ULT DISPL [mm] & 84.35 & 97.60 & 79.02 & 81.68 & 87.05 & 76.06 & 82.80 & 76.98 \\
\hline & $\begin{array}{c}\text { INITIAL STIFFNESS } \\
{[\mathrm{kN} / \mathrm{mm}]}\end{array}$ & 3.03 & 1.63 & 3.98 & 4.19 & 2.14 & 3.80 & 2.78 & 4.19 \\
\hline & TOT CUM ENERGY [kNmm] & 21332 & 20931 & 41840 & 26633 & 13679 & 22333 & 31734 & 35668 \\
\hline & VISCOUS DAMPING & 0.12 & 0.13 & 0.12 & 0.12 & 0.12 & 0.12 & 0.13 & 0.13 \\
\hline \multirow{5}{*}{50} & MAX LOAD [kN] & 105.19 & 86.53 & 175.09 & 136.62 & 98.64 & 193.84 & 133.19 & 162.03 \\
\hline & ULT DISPL [mm] & 81.89 & 84.30 & 77.76 & 80.71 & 84.73 & 55.35 & 81.76 & 79.62 \\
\hline & $\begin{array}{c}\text { INITIAL STIFFNESS } \\
{[\mathrm{kN} / \mathrm{mm}]}\end{array}$ & 3.75 & 2.96 & 4.28 & 3.57 & 3.16 & 4.76 & 4.06 & 4.06 \\
\hline & TOT CUM ENERGY [kNmm] & 33154 & 37675 & 52097 & 37424 & 24279 & 25388 & 33290 & 36950 \\
\hline & VISCOUS DAMPING & 0.12 & 0.13 & 0.13 & 0.12 & 0.13 & 0.12 & 0.14 & 0.12 \\
\hline
\end{tabular}

NSM retrofitting guaranteed higher values of dissipated energy when compared to unreinforced ones for both infill and timber walls, being the difference more important for timber frame walls. 
The vertical load level tended to increase moderately the dissipative capacity of the walls.

Table 1 shows the results on the main values for all walls. In terms of maximum values, apart from retrofitting performed with bolts, generally steel plates and NSM steel flat bars retrofitting techniques tended to play a major role in the lateral resistance of the walls, reaching an increase in terms of maximum load capacity up to almost $200 \%$, for the lower load level and $70 \%$ for the higher. For all kind of strengthening, the loss in terms of ultimate displacement was usually in the order of $3 \%$ or less. Considering the values of viscous damping, the values obtained for the retrofitted walls retrofitted are similar for all retrofitting solutions, pointing out that an innovative retrofitting technique could be a comparable alternative to a traditional one when approaching a strengthening problem.

\section{Future developments}

Future developments for this work include the definition of an analytical hysteretic model for traditional timber frame walls based on experimental results and execution of numerical models calibrated on the experimental results obtain in order to perform parametric analyses.

\section{Conclusions}

Aiming at gathering a better insight on the seismic response of traditional timber frame walls, characteristic of ancient construction all over the world, and on the improvement of their seismic performance, an experimental campaign was designed based on static cyclic tests, taking into consideration different types of infill and different retrofitting solutions.

As concluding remarks, it is important to point out some results of this work: (1) the presence of infill changes considerably the response of the walls in terms of predominant resisting mechanism, due to the confining effect on the timber frame; (2) the retrofitting technique with steel plates greatly increased the stiffness of the walls, particularly when the diagonal elements were linked to the main frame, while the NMS steel flat bars proved to be more appropriate for timber frame walls, since the deformation of the timber elements was not hindered by the infill and the exploitation of the flat bars was greater; (3) for all walls, damages were concentrated in the connections, pointing out their key role in the response of the walls.

\section{Acknowledgements}

The authors would like to acknowledge Eng. Filipe Ferreira and A.O.F. (Augusto Oliveira Ferreira \& C Lda.) for their expertise and collaboration in the construction of the wall specimens.

The first author would also like to acknowledge the Portuguese Science and Technology Foundation (FCT) for its financial support through grant SFRH / BD / 61908 / 2009.

\section{References}

[1] Vasconcelos G., Poletti E., Salavessa E., Jesus A., Lourenço P.B., Pilaon P., 2013, In plane shear behaviour of traditional timber walls, Engineering Structures, 56: 1028-1048.

[2] Langenbach R., 2009, Don't tear it down! Preserving the earthquake resistant vernacular architecture of Kashmir, New Delhi, UNESCO.

[3] ISO DIS 21581, 2009, Timber structures - Static and cyclic lateral load test method for shear walls.

[4] Poletti E., Vasconcelos G., 2013, Seismic behaviour and retrofitting of timber frame walls, International conference on structural health assessment of timber structures (SHATIS'13) 4 - 6 September, Trento, Italy. 